\title{
Decellularization reduces immunogenicity of sheep pulmonary artery vascular patches
}

\author{
Eric J. Lehr, MD, PhD, ${ }^{\mathrm{a}}$ Gina R. Rayat, $\mathrm{PhD},{ }^{\mathrm{b}}$ Brian Chiu, $\mathrm{MD},{ }^{\mathrm{c}}$ Thomas Churchill, $\mathrm{PhD},{ }^{\mathrm{b}}$ \\ Locksley E. McGann, PhD, ${ }^{\mathrm{c}}$ James Y. Coe, MD, ${ }^{\mathrm{d}}$ and David B. Ross, $\mathrm{MD}^{\mathrm{b}}$
}

\begin{abstract}
Objectives: Allograft vascular tissue is important in the repair of complex structural lesions of the heart and great vessels, but induces a deleterious immune response that might shorten the effective lifespan of the tissue and sensitize the recipient. We hypothesized that decellularizing allograft vascular tissue reduces the host allogeneic immune response.
\end{abstract}

\begin{abstract}
Methods: Allograft ovine pulmonary artery patches were decellularized, cryopreserved, and implanted into the descending thoracic aorta. The humoral immune response was measured by means of flow cytometry at regular intervals over 6 months. Graft histology, immunohistochemistry, and calcification were assessed after 4 weeks or 6 months.
\end{abstract}

Results: Leukocyte infiltration was reduced in decellularized grafts. A trend toward decreased in-patch calcification was observed in the decellularized group $(7.6 \pm 4.3 \mathrm{vs} 40.0 \pm 15.9 \mathrm{mg}$ of calcium $/ \mathrm{mg}$ of protein, $P=.107)$. Decellularization reduced IgG antibody binding to donor splenocytes $(9.8 \% \pm 3.3 \% \mathrm{vs} 57.8 \% \pm$ $13.7 \%$ [control value], $P=.010$ ), as assessed by means of flow cytometry. All cytokines examined were detected in nondecellularized tissues after 4 weeks but not at 6 months, indicating complete graft rejection at that time. In contrast, transforming growth factor $\beta 1$ and interleukin 10 were the only prominent cytokines in all decellularized grafts at 4 weeks after transplantation.

Conclusions: Decellularization of allograft vascular tissue minimized the recipient cellular immune response and eliminated the production of anti-donor antibodies in recipients. (J Thorac Cardiovasc Surg 2011;141:1056-62)

\begin{abstract}
Allograft cardiovascular tissue has been used to reconstruct congenital and acquired lesions of the heart and great vessels in pediatric and adult populations since the 1950s. Cryopreserved allograft vascular tissue has superior handling characteristics, provides an excellent hemodynamic profile, and does not require anticoagulation, but elicits a strong cellular and humoral ${ }^{1-3}$ immune response in recipients. Allograft valve conduits incite the development of anti-human leukocyte antigen class I and II antibodies ${ }^{4}$ that remain detectable after 8 years. ${ }^{5}$ Although the significance of this humoral immune response is debated, ${ }^{6}$ it might accelerate the deterioration of the allograft, resulting in structural valve failure $^{7,8}$ and reduced freedom from reoperation ${ }^{9}$ and might complicate future heart transplantation. ${ }^{10,11}$ The host
\end{abstract}

From the Division of Cardiac Surgery, ${ }^{\text {a }}$ University of Maryland School of Medicine, Baltimore, Md; and the Departments of Surgery, ${ }^{\mathrm{b}}$ Laboratory Medicine and Patho$\operatorname{logy},{ }^{\mathrm{c}}$ and Pediatrics, ${ }^{\mathrm{d}}$ University of Alberta, Edmonton, Alberta, Canada.

Funding for this work was provided by the University Hospital Foundation and the Edmonton Civic Employees Foundation. E.J.L. received funding as a Canadian Institutes of Health Research Strategic Training Fellow in TORCH (Tomorrow's Research Cardiovascular Health Professionals). G.R.R. is a Canadian Diabetes Association Scholar.

Disclosures: Authors have nothing to disclose with regard to commercial support.

Received for publication Oct 18, 2009; revisions received Jan 25, 2010; accepted for publication Feb 14, 2010; available ahead of print July 16, 2010.

Address for reprints: Eric J. Lehr, MD, PhD, Division of Cardiac Surgery, University of Maryland, Baltimore, MD, 21201 (E-mail: elehr@smail.umaryland.edu).

0022-5223/\$36.00

Copyright (c) 2011 by The American Association for Thoracic Surgery doi:10.1016/j.jtcvs.2010.02.060 immune response is more profound in younger age groups and might accelerate the destruction of the allograft in this population.

Cellular elements in the graft might be primarily responsible for the allogeneic immune response. An attractive strategy is to target the conduit. Decellularizing the allograft might attenuate the host's immune response ${ }^{12}$ by eliminating major histocompatibility complex antigens on the conduit. No studies to date have measured the development of anti-donor antibody in a large-animal model. We intended to assess the long-term effect of graft decellularization on cellular and humoral immune responses in sheep.

\section{MATERIALS AND METHODS}

Approval for this study was obtained from the University of Alberta Animal Care and Use Committee. The funding organizations assumed no role in data collection, analysis, interpretation, or the right to approve or disapprove publication of the final manuscript.

\section{Experimental Animals}

Suffolk sheep were purchased from a local farm and housed at the University of Alberta farm in accordance with the guidelines of the Canadian Council on Animal Care. ${ }^{13}$ They were provided standard food and water ad libitum. Mixed lymphocyte reaction assays were performed, as previously described, to ensure allogenicity between donor and recipient pairs. ${ }^{14}$

\section{Donor Patch Procurement and Preparation}

After achievement of general halothane anesthesia, by using aseptic techniques, a large trapdoor incision was made over the left hemithorax, 


$$
\begin{aligned}
\text { Abbreviations and Acronyms } \\
\begin{aligned}
\text { FACS } & \text { fluorescence-activated cell sorting } \\
\text { IFNG } & =\text { interferon } \\
\text { IL } & =\text { interleukin } \\
\text { RT-PCR }= & \text { reverse transcription-polymerase } \\
& \text { chain reaction } \\
\text { TGFB }= & \text { transforming growth factor } \beta
\end{aligned}
\end{aligned}
$$

and the animal was exsanguinated. Donor pulmonary arteries were immediately procured in a manner similar to the Ross procedure and transported inRPMI culture media (Gibco, Grand Island, NY). Donor tissue was decellularized in a series of hypotonic and hypertonic tris(hydroxymethyl)aminomethane (tris) buffers with $0.5 \%$ polyethylene glycol p- $(1,1,3$, 3-tetramethylbutyl)-phenyl ether (Triton X-100; Labchem, Inc, Pittsburgh, $\mathrm{Pa}$ ) as a detergent, as previously described. ${ }^{15}$ Control tissues were prepared similarly but were not decellularized before cryopreservation.

\section{Cryopreservation}

Following the protocol of our tissue bank, decellularized and control tissues were sterilized in antibiotic solution (colistimethate [Sterimax, Inc, Mississauga, Ontario, Canada], vancomycin hydrochloride [Pharmascience, Inc, Montreal, Quebec, Canada], lincomycin [Pharmacia, Kirkland, Quebec, Canada], and cefoxitin sodium [Novopharm, Toronto, Ontario, Canada]) for 24 hours. Valve conduits were rinsed and transferred into $7.5 \% \mathrm{Me}_{2} \mathrm{SO}$ (Fisher Scientific, Fair Lawn, NJ) in X-Vivo (Cambrex Bio Science, Walkersville, Md), packaged, and frozen over 5 phases (Cryomed 1010; Cryomed, Mount Clements, Mich). Tissues were cooled from ambient temperature to $4{ }^{\circ} \mathrm{C}$, supercooled to $-2^{\circ} \mathrm{C}$, and seeded by applying a burst of vapor-phase nitrogen to initiate ice formation in the supercooled sample. Cooling proceeded at $1^{\circ} \mathrm{C} / \mathrm{min}$ to $-50^{\circ} \mathrm{C}$ and then at $7^{\circ} \mathrm{C} / \mathrm{min}$ until the allograft reached $-100^{\circ} \mathrm{C}$. Conduits were stored in vapor-phase liquid nitrogen.

\section{Implant Procedure}

Donor tissue was thawed, and a $2 \times 4-\mathrm{cm}$ diamond-shaped patch was cut from the main pulmonary artery and implanted in the descending thoracic aorta, as previously described. ${ }^{16}$ In short, recipient animals were anesthetized with halothane and nitrous oxide. After oral-tracheal intubation, ampicillin (1 g, Novopharm), gentamicin (1 g; Sandoz, Princeton, $\mathrm{NJ}$ ), and rocuronium (50 mg; Organon Canada Ltd, Toronto, Ontario, Canada) were administered intravenously. Under aseptic conditions, a thoracotomy was performed in the fifth left intercostal space. An aortotomy was made, and the donor patch was sutured in place. An intra-aortic shunt was used to minimize the risk of paralysis. Recipient animals were killed by means of exsanguination, and the patches were explanted 4 weeks (decellularized, $\mathrm{n}=6$; control, $\mathrm{n}=4$ ) or 6 months (decellularized, $\mathrm{n}=5$; control, $\mathrm{n}=8$ ) after implantation to assess the early and late immune response.

\section{Immunohistochemistry}

Explanted grafts were fixed and embedded in paraffin and then sectioned $(5 \mu \mathrm{m})$ and stained with hematoxylin and eosin and Movat's pentachrome. Other sections of the explanted grafts were stained for interstitial cells (mouse anti-vimentin, 1:50; Dako Cytomation, Mississauga, Canada), endothelial cells (anti-CD31 [MCA1812], 1:50, Serotec, Kidlington, United Kingdom, and anti-von Willebrand factor [AB7356], 1:100, Chemicon International, Temecula, Calif), B cells, (murine anti-CD79 $\alpha$ cy [M7051], 1:200, Dako), and transforming growth factor $\beta$ (TGFB; anti-human TGFB [MCA797], 1:100, Serotec). Suitable antibodies against ovine T cells were not available. Positive reactions were detected by using standard staining techniques with biotinylated secondary antibodies, peroxidase avidinbiotin complex, and diaminobenzidine as a substrate for the enzyme. Slides were examined with an Axioscope II equipped with an AxioCam MRc camera and AxioVision 3.1 software (Carl Zeiss, Göttingen, Germany).

\section{Electron Microscopy}

Sections of explanted patches were prefixed in $2.5 \%$ glutaraldehyde in Millonig's buffer ( $\mathrm{pH}$ 7.2), washed in the same buffer, and placed in $1 \%$ $\mathrm{OsO}_{4}$. After washing in distilled water, samples were dehydrated in ethanol. Samples were dried in a $\mathrm{CO}_{2}$ critical-point dryer (Seevac, Inc, Pittsburgh, $\mathrm{Pa}$ ), mounted on aluminum stubs, and sputter coated with gold (Edwards Sputter Coater, S150B). Digital micrographs of samples were taken with a Hitachi Scanning Electron Microscope S2500 (Hitachi, Tokyo, Japan), as previously described. ${ }^{17}$

\section{Determination of Humoral Response}

Sheep anti-sheep IgG antibodies in recipient blood serum were measured by means of flow cytometry, as previously described. ${ }^{18}$ Briefly, donor splenocytes were isolated and frozen at a concentration of $2.5 \times 10^{7} \mathrm{~mL}$ in $10 \%$ $\mathrm{Me}_{2} \mathrm{SO}$ and fetal bovine serum at $-86^{\circ} \mathrm{C}$. Serum was collected from the blood of recipient animals at the time of implantation, weekly for 4 weeks, and then monthly until the end of the experimental period and kept frozen at $-86^{\circ} \mathrm{C}$. Splenocytes were thawed, washed in fluorescence-activated cell sorting (FACS) buffer (phosphate-buffered saline and 1\% fetal bovine serum; Sigma, Oakville, Canada), resuspended (2.5 million cells $/ \mathrm{mL})$ in $50 \mu \mathrm{L}$ of recipient serum (1:8 dilution in FACS buffer), and incubated at $37^{\circ} \mathrm{C}$ in a humidified atmosphere of $5 \% \mathrm{CO}_{2}$ for 1 hour. Splenocytes were then washed and incubated with $50 \mu \mathrm{L}$ of fluorescein isothiocyanteconjugated AffiniPure rabbit anti-sheep IgG Fc fragment-specific antibody (313-095-046, 1:200 dilution in FACS buffer; Jackson ImmunoResearch Laboratories, Inc, West Grove, Pa) in the dark for 30 minutes at $4{ }^{\circ} \mathrm{C}$. The percentage of cells bound to antibody was detected from single-parameter fluorescence histograms on a flow cytometer after gating on viable splenocytes with Cellquest software for analysis (FACSCalibur; BD Biosciences, Ontario, Canada). Controls for this experiment include sera taken at baseline, unstained donor splenocytes, and donor splenocytes with secondary antibody without recipient serum.

\section{Calcification}

Calcification is a common mode of allograft vascular conduit failure in the clinical setting. Therefore calcium concentrations in the explanted samples were determined according to the methods described by Sarkar and Chauhan $^{19}$ and Lowry and colleagues ${ }^{20}$ and presented as micrograms per milligram of protein.

\section{RNA Isolation and Reverse Transcription- Polymerase Chain Reaction}

Samples of explanted patches taken away from the suture line were crushed in liquid nitrogen and dissolved in $1 \mathrm{~mL}$ of Trizol reagent (Invitrogen, Carlsbad, Calif), and RNA was extracted. cDNA was constructed from $1 \mu \mathrm{g}$ of total RNA by using MultiScribe Reverse Transcriptase (Applied Biosystems, Foster City, Calif), according to the manufacture's protocol, and $1 \mu \mathrm{L}$ of cDNA was amplified with AmpliTaq Gold (Applied Biosystems). The polymerase chain reaction conditions were as follows: cDNA was denatured at $95^{\circ} \mathrm{C}$ for 9 minutes, followed by amplification for 40 cycles at $95^{\circ} \mathrm{C}$ for 30 seconds and annealing at $60^{\circ} \mathrm{C}$ for 30 seconds, with a final extension of $72^{\circ} \mathrm{C}$ for 12 minutes using primer pairs that span at least 1 intron (Table 1). Polymerase chain reaction products were separated on an ethidium bromide (Sigma)-stained agarose gel $(1.5 \%)$, and images were captured with Alpha Digidoc software (PerkinElmer, Waltham, Mass). Bands of the expected size were ligated in the pCR5-TOPO vector (TOPO TA Cloning Kit for Sequencing, Invitrogen), sequenced (University of Alberta 
TABLE 1. Primers used for PCR amplification

\begin{tabular}{|c|c|c|c|c|}
\hline Gene & Size (bp) & Strand & Sequence $5^{\prime}-3^{\prime}$ & GenBank ID \\
\hline \multirow[t]{2}{*}{ IL-2 } & 214 & $\mathrm{~F}$ & $\begin{array}{c}\text { ATG CCC AAG GTT } \\
\text { AAC GCT AC }\end{array}$ & AF287479 \\
\hline & & $\mathrm{R}$ & $\begin{array}{c}\text { CAG CCT TTA CTG } \\
\text { TCG CAT CA }\end{array}$ & \\
\hline \multirow[t]{2}{*}{ IL-4 } & 206 & F & $\begin{array}{c}\text { GTA CCA GCC ACT } \\
\text { TCG TCC AT }\end{array}$ & NM_001009313 \\
\hline & & $\mathrm{R}$ & $\begin{array}{c}\text { GCA CAT GTG GCT } \\
\text { CCT GTA GA }\end{array}$ & \\
\hline \multirow[t]{2}{*}{ IL-10 } & 201 & F & $\begin{array}{l}\text { TGT TGA CCC AGT } \\
\text { CTC TGC TG }\end{array}$ & NM_001009327 \\
\hline & & $\mathrm{R}$ & $\begin{array}{c}\text { AGG GCA GAA AAC } \\
\text { GAT GAC AG }\end{array}$ & \\
\hline \multirow[t]{2}{*}{ IFNG } & 236 & $\mathrm{~F}$ & $\begin{array}{l}\text { TAA GGG TGG GCC } \\
\text { TCT TTT CT }\end{array}$ & NM_001009803 \\
\hline & & $\mathrm{R}$ & $\begin{array}{c}\text { CAT CCA CCG GAA } \\
\text { TTT GAA TC }\end{array}$ & \\
\hline \multirow[t]{2}{*}{ TNFA } & 335 & $\mathrm{~F}$ & $\begin{array}{l}\text { GGC TCT CCT GTC } \\
\text { TCC CGT }\end{array}$ & NM_001024860 \\
\hline & & $\mathrm{R}$ & $\begin{array}{l}\text { ATT GAT GGC TTT } \\
\text { GCG CTG }\end{array}$ & \\
\hline \multirow[t]{2}{*}{ TGFB1 } & 157 & $\mathrm{~F}$ & $\begin{array}{c}\text { CAC GTG GAG CTG } \\
\text { TAC CAG AA }\end{array}$ & NM_001009400 \\
\hline & & $\mathrm{R}$ & $\begin{array}{c}\text { GGC GAA AGC CTT } \\
\text { CTA TTT CC }\end{array}$ & \\
\hline \multirow[t]{2}{*}{ GAPDH } & 310 & $\mathrm{~F}$ & $\begin{array}{c}\text { AAT CCC ATC ACC } \\
\text { ATC TTC CA }\end{array}$ & NM_008084 \\
\hline & & $\mathrm{R}$ & $\begin{array}{c}\text { GGC AGT GAT GGC } \\
\text { ATG GAC TG }\end{array}$ & \\
\hline
\end{tabular}

$I L$, Interleukin; $F$, forward; $R$, reverse; $I F N$, interferon; $T N F$, tumor necrosis factor; $T G F$, transforming growth factor; $G A P D H$, glyceraldehyde-3-phosphate dehydrogenase.

DNA Core Laboratory), and compared with known GenBank sequences. The positive control consisted of sheep spleen cDNA, and the negative control, which consisted of water in place of experimental cDNA and glyceraldehyde-3-phosphate dehydrogenase (housekeeping gene), ensured cDNA integrity.

\section{Statistical Analysis}

Continuous data were expressed as the mean \pm standard error of the mean. Means of multiple groups were compared by means of 1-way analysis of variance with Scheffe post hoc analysis to compare individual groups by using SPSS 13.0 software (SPSS, Inc, Chicago, Ill).

\section{RESULTS}

\section{Clinical Results}

A single animal receiving a decellularized patch died 61 days after implantation. At autopsy, the patch had dehisced in the setting of empyema and a large abscess surrounding the aorta at the surgical site. No other animals had significant morbidities or mortality. On explantation, all decellularized patches appeared to be well healed by 4 weeks without evidence of aneurysmal dilation or major tissue failure on gross examination (Figure 1).
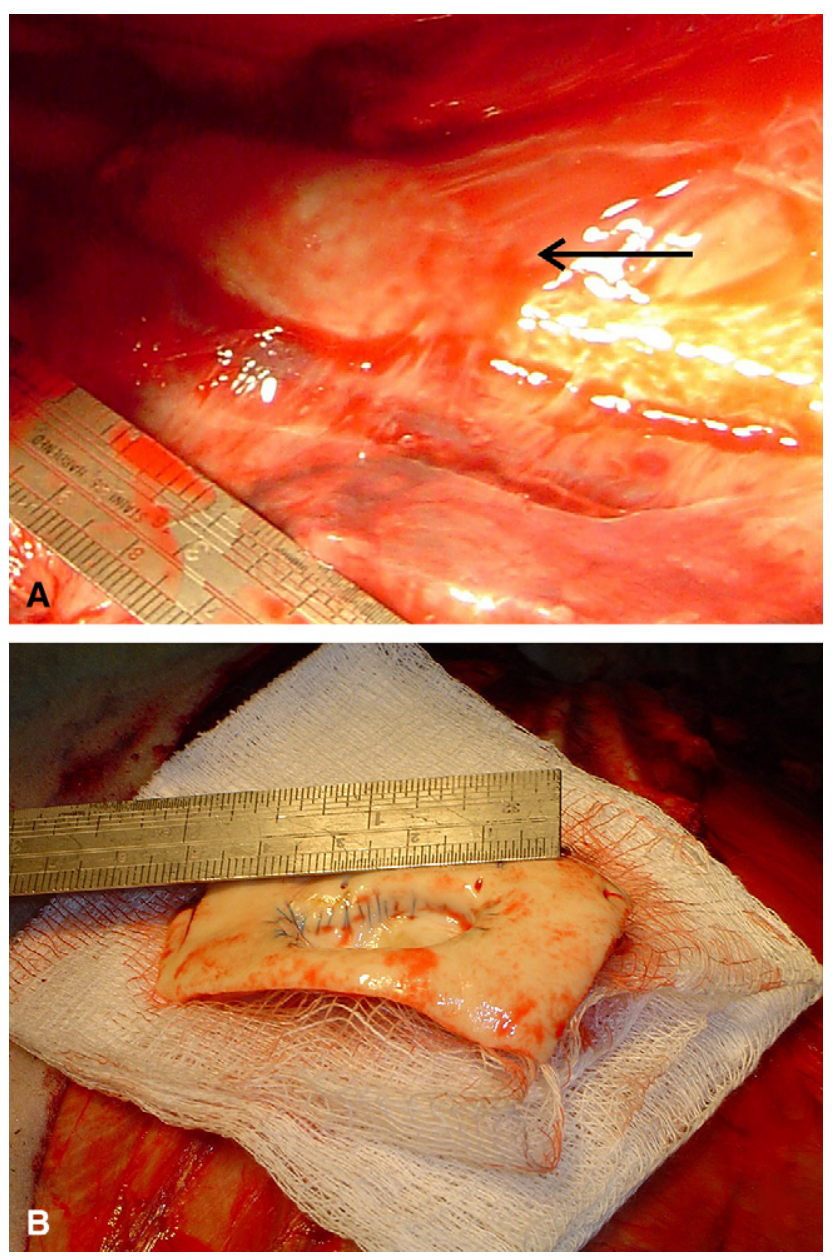

FIGURE 1. Gross pathology of decellularized patch implanted for 6 months at the time of explantation in situ (A) and immediately after explantation (B).

\section{Histology and Immunohistochemistry}

Histologic assessment of the tissue before implantation confirmed effective decellularization (Figure 2). No endothelium was present, and only ghosts of cells were appreciable, whereas the internal and external elastic lamina were preserved, as was the vaso vasorum. Four weeks after implantation, control patches demonstrated findings consistent with immune rejection (Figure 3). There was profound cellular neointimal hyperplasia, and the media were edematous and hypercellular with neovascularization. Hematoxylin and eosin staining revealed lymphocytic infiltrates primarily near the border of the external elastic lamina. The internal and external elastic lamina were fragmented, as shown by means of Movat's pentachrome staining, and smooth muscle cell proliferation in the media was evident, as determined by means of vimentin staining. There was increased vascularity of the adventitia with thickened blood vessels, as shown with CD31 and von Willebrand factor staining. None of the cells in the infiltrate stained positive for B cells (CD79, 

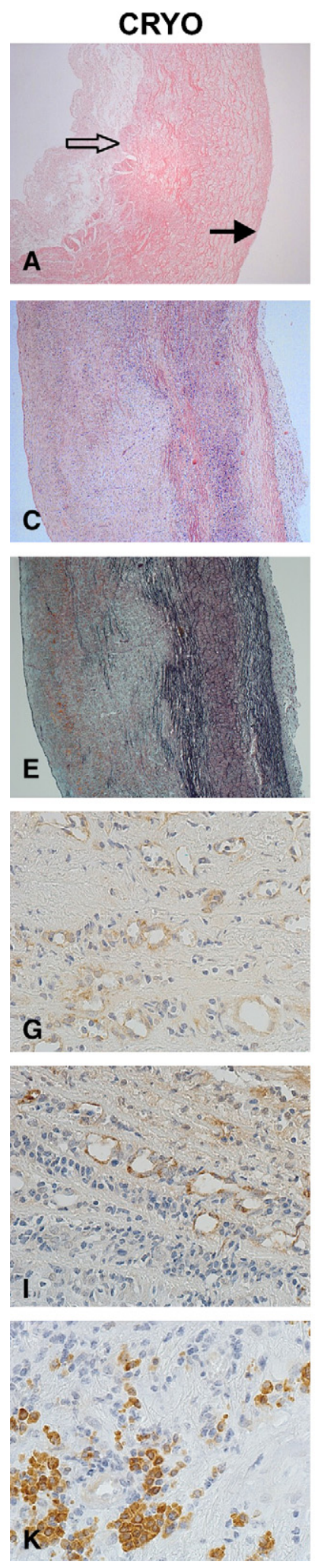

FIGURE 2. Photomicrographs of representative sections of nondecellularized and decellularized allogeneic ovine pulmonary artery patches at the time of implantation (A and B) and 4 weeks after implantation (C-J). Samples were fixed in formaldehyde, embedded in paraffin, and sectioned
Figure 3). Similar findings were seen in control patches at 6 months (Figure 2).

Decellularized grafts demonstrated fewer features consistent with immune rejection, although evidence of inflammation remained (Figure 2). Specifically, there was minimal lymphocyte infiltrate in the decellularized graft at 4 weeks and 6 months. The endothelial layer of the vaso vasorum was much thinner compared with control patches. B cells (CD79) were not identified in decellularized patches at 4 weeks or 6 months after implantation (Figure 2). TGFB was strongly expressed, particularly at the medial-adventitial junction at 4 weeks and 6 months in control patches but only in occasional spindle cells in decellularized patches at 4 weeks (data not shown).

\section{Scanning Electron Microscopy}

Scanning electron microscopy of explanted grafts demonstrated white blood cells on the surface of nondecellularized grafts at 4 weeks. White blood cells were not seen on the endothelial surface of decellularized grafts. The intimal surface was fully re-endothelialized 4 weeks after implantation (Figure 3).

\section{Humoral Response}

Because decellularization attenuated the cellular immune response, we examined the effect of decellularization on the production of recipient anti-donor antibodies. In vivo production of donor-specific antibodies was inhibited by decellularization (Figure 4). When donor sheep cells were incubated with recipient sheep sera, a trend toward reduced binding of alloreactive murine $\mathrm{IgG}$ antibodies to donor splenocytes was identified at 4 weeks $(2.9 \pm 0.6$ [decellularized] vs $24.1 \pm 10.5$ [nondecellularized], $P=.115$, independent samples $t$ test, equal variance not assumed). Antibody production peaked 3 to 4 months after surgical intervention, at which point a significant difference was identified between groups $(9.8 \pm 3.3$ [decellularized] vs $57.8 \pm 13.7$ [nondecellularized], $P=.010$ ).

\footnotetext{
at $5 \mu \mathrm{m}$. A and B represent grafts at the time of implantation (original magnification $40 \times$ ). Solid arrows and open arrows indicate the external and internal lamina, respectively. Early and intense lymphocytic infiltrates are profuse in nondecellularized patches but virtually absent in decellularized grafts ( $\mathrm{C}$ and $\mathrm{D}$, original magnification $40 \times$ ). Both decellularized and nondecellularized grafts show thickening of the intima and adventitia, as well as disruption of the external elastic lamina with myofibroblastic proliferation (Movat's pentachrome stain, E and F, original magnification 40×). Neovascularization of the adventitia and media with thickened vessels was also detected (von Willebrand factor positive, $\mathrm{G}$ and $\mathrm{H} ; \mathrm{CD} 31^{+}$, I and J; original magnification $100 \times)$. B cells $\left(\mathrm{CD} 79^{+}, \mathrm{K}\right.$ and $\mathrm{L}$, original magnification $100 \times$ ) were identified in the perivascular regions at the medial-adventitial junction in nondecellularized control grafts at 6 months. $C R Y O$, Cryopreserved; CRYO \& DECEL, cryopreserved and decellularized.
} 

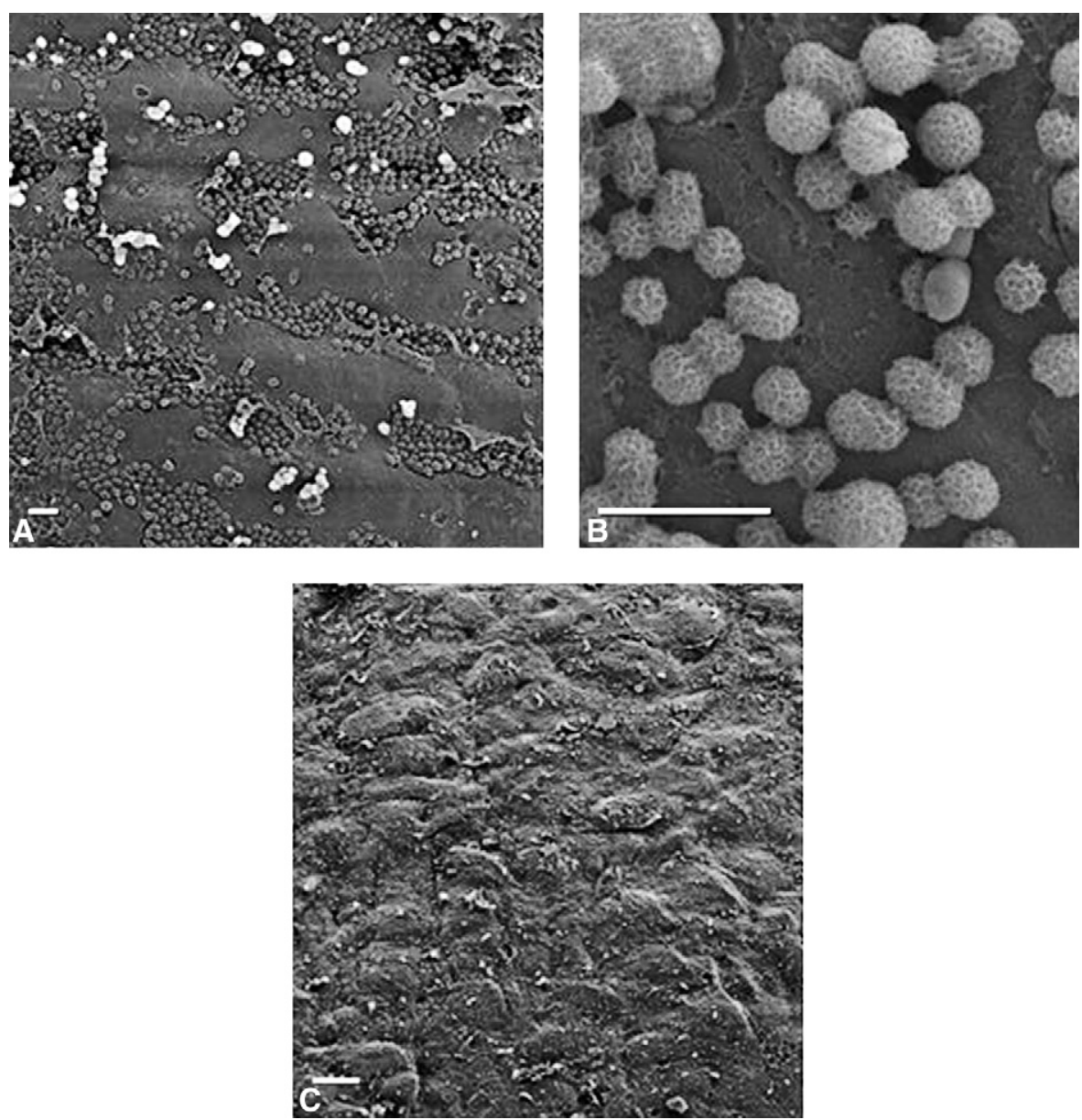

FIGURE 3. Scanning electron microscopy of the endothelial surface of explanted nondecellularized and decellularized pulmonary artery patches at 4 weeks after implantation. Both nondecellularized control (A and B) and decellularized (C) patches show re-endothelialization, but white blood cell infiltrate is identified only on nondecellularized control grafts. The bar indicates $10 \mu \mathrm{m}$ in all electron micrographs.

\section{Cytokine Expression}

mRNA transcripts for interferon $\gamma$ (IFNG, $\mathrm{T}_{\mathrm{H}} 1$ cytokine), interleukin (IL) 10 ( $\mathrm{T}_{\mathrm{H}} 2$ cytokine), and TGFB1 (regulatory cytokine) were identified by means of reverse transcriptionpolymerase chain reaction (RT-PCR) in all nondecellularized grafts at 4 weeks. Fewer decellularized grafts expressed IL-10 $(67 \%)$ and IFNG $(67 \%)$ at 4 weeks, but TGFB1 was expressed in all grafts at 4 weeks (data not shown). mRNA transcripts for IL-4 were found in 2 of 4 nondecellularized grafts at 4 weeks but were not detected in any of the decellularized grafts. Fifty percent of both decellularized and nondecellularized grafts expressed tumor necrosis factor $\alpha$. Seventy-five percent of nondecellularized grafts expressed IL- 2 at 4 weeks, whereas IL-2 was expressed in only $50 \%$ of decellularized grafts. Taken together, these results show that all cytokines examined were detected in nondecellularized control allografts at 4 weeks but not at 6 months after transplantation, indicating that there was complete cellular and humoral rejection of the graft at this time. In addition, decellularization reduced both $\mathrm{T}_{\mathrm{H}} 1$ and $\mathrm{T}_{\mathrm{H}} 2$ cytokines.

\section{Calcification}

Calcification frequently causes allograft vascular tissue to fail in the clinical setting. Therefore we sought to determine the effect of decellularization on patch calcification by assessing calcium levels in the grafts at 4 weeks and 6 months. A trend toward a reduction in calcification was observed in the decellularized group $(7.6 \pm 4.3$ vs $40.0 \pm 15.9 \mathrm{mg}$ of calcium $/ \mathrm{mg}$ of protein, $P=.107)$.

\section{DISCUSSION}

Allograft valves and conduits have become a mainstay in the surgical treatment of congenital heart defects but have specific limitations leading to important clinical problems, especially for the pediatric population. With current technology, the problem of an imperfect donor allograft eliciting a host immune response cannot be satisfactorily controlled. Allogeneic valve grafts induce a host immune response that might cause structural deterioration of the valve that is perhaps the major obstacle to long-term graft viability. Immunosuppressive agents might temper the host's immune 


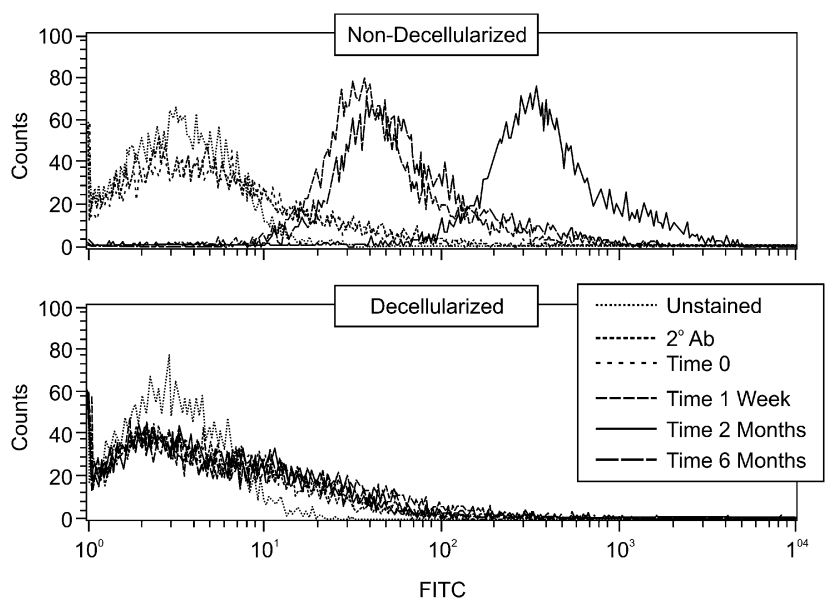

FIGURE 4. Flow cytometric determination of the humoral response of sheep receiving allograft pulmonary artery patches. Recipient generation of anti-donor IgG peaks at 2 months after implantation. Decellularization of donor pulmonary artery patches eliminates the development of the recipient humoral immune response. $2^{\circ} \mathrm{Ab}$, Secondary antibody alone; FITC, fluorescein isothiocyanate.

response but would likely be fraught with a new set of complications related to immune suppression. Alternatively, the allograft might be altered by eliminating alloantigens so that the host immune response is not activated.

The current communication provides evidence that decellularization of the graft in a large animal model can eliminate both cellular and donor-specific humoral immune responses. Without decellularization, infiltration of mononuclear immune cells was evident 4 weeks after implantation; this finding was persistent after 6 months and was confirmed by electron microscopy. At 4 weeks, B cells (CD79 $)$ were absent in the graft, but at 6 months, there was a population of B cells among the infiltrating immune cells. Decellularization was effective at reducing the cellular infiltrate because no immune cells were identified at either 4 weeks or 6 months after implantation.

There was a profound humoral immune response in animals receiving nondecellularized control patches, as evidenced by means of flow cytometry, that peaked between 3 and 4 months and then began to decrease, as expected, when the primary response subsides. In contrast, animals receiving decellularized patches failed to generate any detectable anti-donor antibodies. The complete lack of antibody levels above those seen in control animals, as well as the lack of B cells in the patches, indicates a complete prevention of the donor-specific humoral response against the grafts.

The mechanisms of cell signaling after implantation of allografts or decellularized allografts have not been elucidated in either small- or large-animal models. Our results provide initial insights into 2 putative pathways that might be active. By means of RT-PCR analysis, we demonstrated that decellularization reduced the number of grafts expressing $T_{H} 1$ cytokines (IFNG) and $\mathrm{T}_{\mathrm{H}} 2$ cytokines (IL-10), but there was no change in the number of grafts expressing TGFB1. These results further suggest that rejection of the allograft vascular patch is mediated by both cellular and humoral immune responses and that decellularization attenuates both of these response mechanisms. In contrast, upregulation of TGFB1 might be a generalized response to the operation or represent a non-antigen-dependent generalized response to vascular injury. TGFB1 protein was not identified in the decellularized patches; however, mRNA transcripts for this cytokine were identified at 4 weeks. Although the literature reports divergent roles for TGFB1, Schulick and associates ${ }^{21}$ demonstrated that local upregulation of TGFB1 results in cartilaginous metaplasia of the arterial wall and intimal growth. This ongoing signal by TGFB1 might be the stimulus for the profound endothelial hyperplasia seen in both nondecellularized control patches and decellularized patches. At 6 months, IFNG and IL-10 were no longer expressed in nondecellularized control patches, suggesting that the graft was completely rejected at this time. Similarly, at 6 months, TGFB1 was not detected on tissue sections or in RT-PCR analysis, further suggesting that the non-antigendependent response had also subsided. Additional work is required to delineate further the cytokine pathways involved in allograft rejection and in the response to the surgical procedure. Future work might lead to adjunctive treatments that could be beneficial in extending the durability of allograft and tissue-engineered valve replacements. Although the observed cellular response and in-graft cytokine production might be representative of a general inflammatory reaction against the implanted tissue, the humoral response confirms anti-donor-specific reactivity.

Calcification is a common mechanism of allograft conduit failure in the clinical setting. Other authors recently demonstrated a reduction of valve calcification at 20 and 52 weeks in a decellularized sheep model. ${ }^{22}$ We observed a trend toward reduced calcification in decellularized grafts compared with that seen in nondecellularized control patches that did not reach statistical significance, perhaps because of the small number of samples in each group. Evidence for structural changes in both control and decellularized patches after implantation was also identified. The mechanism of these changes is not evident based on this work, but it is unlikely that these changes are an antigen-directed immune response or related to the decellularization process given the lack of antibody production and immune cell infiltrate. Moreover, similar changes were identified in control and experimental patches. It is possible that the cryopreservation method created an injury that was not apparent based on histology but manifests after implantation or that cryopreservation causes injury, leading to a generalized tissue-directed host inflammatory response. It remains to be determined whether decellularized valves are structurally weaker than standard cryopreserved valves. Decellularized porcine valves implanted in the pediatric population elicited a profound 
inflammatory response, resulting in rapid degeneration of the valve wall and leaflets. ${ }^{23}$ The mechanisms resulting in failure of these decellularized xenograft valves have not been fully elucidated, but might be related to incomplete decellularization, the decellularization process, or a xenogeneic immune response. ${ }^{24} \mathrm{We}$ did not observe any structural failures or aneurysm formation in either nondecellularized control or decellularized patches.

Implanted decellularized patches showed myofibroblastic repopulation of the matrix, although at this point, their potential for contribution toward growth and repair is not clear. The fact that the decellularized matrix can support infiltrating cells suggests that tissue-engineering strategies could capitalize on this property. Indeed, decellularized heart matrices have served as a scaffold for the regeneration of functioning organs in vitro. ${ }^{25}$ Either the graft or the repopulating cells could be manipulated to enhance repopulation and cell function in the repopulated graft.

In conclusion, we provide additional evidence that allograft vascular patch failure might be mediated by means of allorejection. Osmotic lysis with detergent effectively decellularized ovine pulmonary artery patches and attenuated both the cellular and humoral allogeneic immune responses in a large-animal model.

We thank Alana Eshpeter, Karen Seeberger, Maria Cabuhat, Ted Pretty, Dawne Colwell, Dr Ming Chen, and Dr Greg Korbutt for their assistance in preparing the manuscript.

\section{References}

1. Meyer SR, Nagendran J, Desai LS, Rayat GR, Churchill TA, Anderson CC, et al. Decellularization reduces the immune response to aortic valve allografts in the rat. J Thorac Cardiovasc Surg. 2005;130:469-76.

2. Hogan P, Duplock L, Green M, Smith S, Gall KL, Frazer IH, et al. Human aortic valve allografts elicit a donor-specific immune response. $J$ Thorac Cardiovasc Surg. 1996;112:1260-6.

3. Hoekstra F, Witvliet M, Knoop C, Akkersdijk G, Jutte N, Bogers A, et al. Donorspecific anti-human leukocyte antigen class I antibodies after implantation of cardiac valve allografts. J Heart Lung Transplant. 1997;16:570-2.

4. Hawkins JA, Breinholt JP, Lambert LM, Fuller TC, Profaizer T, McGough EC, et al. Class I and class II anti-HLA antibodies after implantation of cryopreserved allograft material in pediatric patients. J Thorac Cardiovasc Surg. 2000;119:324-30.

5. Hooper DK, Hawkins JA, Fuller TC, Profaizer T, Shaddy RE. Panel-reactive antibodies late after allograft implantation in children. Ann Thorac Surg. 2005;79: 641-4.

6. Yap CH, Skillington PD, Matalanis G, Davis BB, Tait BD, Hudson F, et al. AntiHLA antibodies after cryopreserved allograft valve implantation does not predict valve dysfunction at three-year follow up. J Heart Valve Dis. 2006;15:540-4.
7. Pompilio G, Polvani G, Piccolo G, Guarino A, Nocco A, Innocente A, et al. Sixyear monitoring of the donor-specific immune response to cryopreserved aortic allograft valves: implications with valve dysfunction. Ann Thorac Surg. 2004; 78:557-63.

8. Dignan R, O'Brien M, Hogan P, Thornton A, Fowler K, Byrne D, et al. Aortic valve allograft structural deterioration is associated with a subset of antibodies to human leukocyte antigens. J Heart Valve Dis. 2003;12:382-90.

9. Yankah AC, Alexi-Meskhishvili V, Weng Y, Schorn K, Lange PE, Hetzer R. Accelerated degeneration of allografts in the first two years of life. Ann Thorac Surg. 1995;60:S71-6.

10. Meyer SR, Campbell PM, Rutledge JM, Halpin AM, Hawkins LE, Lakey JR, et al. Use of an allograft patch in repair of hypoplastic left heart syndrome may complicate future transplantation. Eur J Cardiothorac Surg. 2005;27:554-60.

11. Jacobs JP, Quintessenza JA, Boucek RJ, Morell VO, Botero LM, Badhwar V, et al. Pediatric cardiac transplantation in children with high panel reactive antibody. Ann Thorac Surg. 2004;78:1703-9.

12. Grauss RW, Hazekamp MG, van Vliet S, Gittenberger-de Groot AC, DeRuiter MC. Decellularization of rat aortic valve allografts reduces leaflet destruction and extracellular matrix remodeling. $J$ Thorac Cardiovasc Surg. 2003; 126:2003-10.

13. Olfert FD, Cross BM, McWilliam AA, eds. Guide to the care and use of experimental animals, Vol 1, 2nd ed. Canadian Council of Animal Care; 1993.

14. Lehr EJ, Rayat GR, Desai LS, Coe JY, Korbutt GS, Ross DB. Inbred or outbred? An evaluation of the functional allogenicity of farm sheep used in cardiac valve studies. J Thorac Cardiovasc Surg. 2006;132:1156-61.

15. Meyer SR, Nagendran J, Desai LS, Rayat GR, Churchill TA, Anderson CC, et al. Decellularization reduces the immune response to aortic valve allografts in the rat. J Thorac Cardiovasc Surg. 2005;130:469-76.

16. Lehr EJ, Coe JY, Ross DB. An intra-aortic shunt prevents paralysis during aortic surgery in sheep. J Surg Res. 2007;141:78-82.

17. Megyesi JF, Findlay JM, Vollrath B, Cook DA, Chen MH. In vivo angioplasty prevents the development of vasospasm in canine carotid arteries. Pharmacological and morphological analyses. Stroke. 1997;28:1216-24.

18. Rayat GR, Gill RG. Indefinite survival of neonatal porcine islet xenografts by simultaneous targeting of LFA-1 and CD154 or CD45RB. Diabetes. 2005;54: 443-51.

19. Sarkar BC, Chauhan UP. A new method for determining micro quantities of calcium in biological materials. Anal Biochem. 1967;20:155-66.

20. Lowry OH, Rosebrough NJ, Farr AL, Randall RJ. Protein measurement with the Folin phenol reagent. J Biol Chem. 1951;193:265-75.

21. Schulick AH, Taylor AJ, Zuo W, Qiu CB, Dong G, Woodward RN, et al. Overexpression of transforming growth factor betal in arterial endothelium causes hyperplasia, apoptosis, and cartilaginous metaplasia. Proc Natl Acad Sci U S A. 1998;95:6983-8.

22. Hopkins RA, Jones AL, Wolfinbarger L, Moore MA, Bert AA, Lofland GK. Decellularization reduces calcification while improving both durability and 1-year functional results of pulmonary homograft valves in juvenile sheep. $J$ Thorac Cardiovasc Surg. 2009;137:907-13.

23. Simon P, Kasimir MT, Seebacher G, Weigel G, Ullrich R, Salzer-Muhar U, et al. Early failure of the tissue engineered porcine heart valve SYNERGRAFT in pediatric patients. Eur J Cardiothorac Surg. 2003;23:1002-6.

24. Rieder E, Seebacher G, Kasimir MT, Eichmair E, Winter B, Dekan B, et al. Tissue engineering of heart valves: decellularized porcine and human valve scaffolds differ importantly in residual potential to attract monocytic cells. Circulation. 2005; 111:2792-7.

25. Ott HC, Matthiesen TS, Goh SK, Black LD, Kren SM, Netoff TI, et al. Perfusiondecellularized matrix: using nature's platform to engineer a bioartificial heart. Nat Med. 2008;14:213-21. 